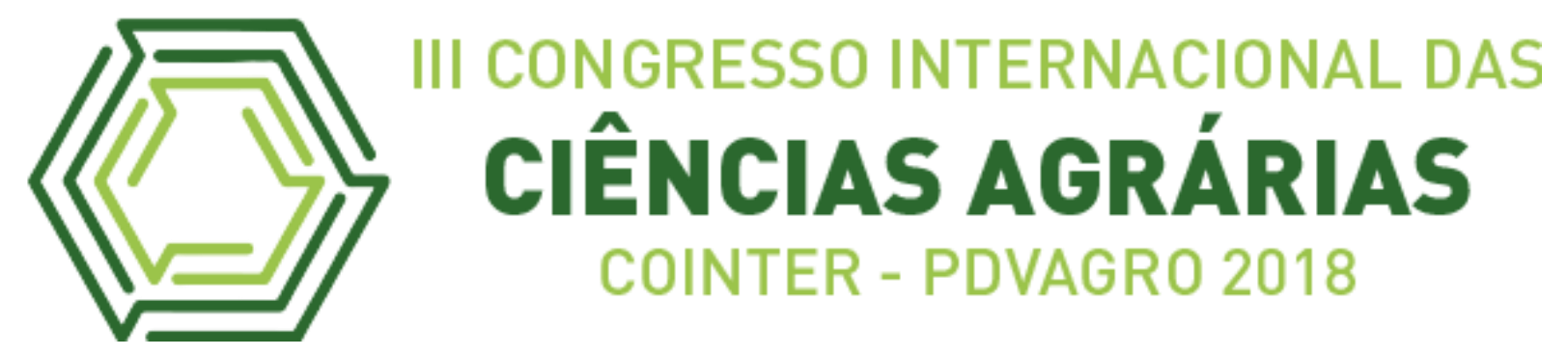

\title{
SENSIBILIZAÇÃO AMBIENTAL ATRAVÉS DA CONSTRUÇÃO DE BRINQUEDOS DE MATERIAIS RECICLÁVEIS
}

\section{ENVIRONMENTAL CONSCIOUS BY THE CONSTRUCTIONS OF TOYS OF RECYCLABLE MATERIALS}

Apresentação: Pôster

\begin{abstract}
Sarah Dia Azevedo ${ }^{1}$; Leandro Marques Torres ${ }^{2}$; Paulo Rick Soares Rodrigues ${ }^{3}$; Cézar Di Paula Da Silva Pinheiro ${ }^{4}$; Débora Prissila Reis Sandim ${ }^{5}$
\end{abstract}

DOI: https://doi.org/10.31692/2526-7701.IIICOINTERPDVAGRO.2018.00661

\section{Introdução}

A Educação ambiental trata-se de uma esfera de fundamental importância no que se refere às interações desenvolvidas no âmbito pessoal e social, e da relação com o meio em que está incluso, de forma compartilhada com diversas formas de vida. Visando induzir dinâmicas socioambientais, a comunidade local e posteriormente ambientes de ampla abrangência, possibilitando uma interação crítica e colaborativa da realidade social e ambiental, fazendo com que o indivíduo tenha uma compreensão autônoma, e criativa, dos diversos problemas existentes que o afetariam de forma direta e suas possíveis soluções (SAUVÉ, L. 2005).

A educação ambiental assume, assim, de maneira crescente, a forma de um processo intelectual ativo, enquanto aprendizado social, baseado no diálogo e interação em constante processo de recriação e reinterpretação de informações, conceitos e significados, que se originam do aprendizado em sala de aula ou da experiência pessoal do aluno (JACOBI, 2005).

A Inclusão de formas lúdicas no ensino surgem como agentes facilitadores do processo de ensino-aprendizagem, onde o aluno seja criança ou adolescente, se sente mais estimulado a participar do processo e aprender o conteúdo de forma mais prazerosa (OLIVEIRA, 2013).

\footnotetext{
1 Engenharia Ambiental e Energias Renováveis, Universidade Federal Rural da Amazônia, saaahazevedo@gmail.com Instituição

2 Engenharia Ambiental e Energias Renováveis, Universidade Federal Rural da Amazônia, leandrotorres15@yahoo.com.br

3 Engenharia Ambiental e Energias Renováveis, Universidade Federal Rural da Amazônia, rickpaulo83@gmail.com

4 Engenharia Ambiental e Energias Renováveis, Universidade Federal Rural da Amazônia, cezarpinheiroo@hotmail.com

${ }^{5}$ Mestranda, Universidade Federal do Pará, deborasandim@gmail.com
} 
Nesse contexto o presente trabalho tem como objetivo a aplicação de práticas de sensibilização ambiental nas crianças do $1^{\circ}$ e $2^{\circ}$ ano do ensino fundamental da escola Centro de Ensino São Bento, por meio de atividades lúdicas como oficina de fantoches de materiais recicláveis, tornando-as capazes de compreender o meio ambiente e o reflexo que ações ambientalmente corretas podem causar ao mesmo.

\section{Fundamentação Teórica}

$\mathrm{Na}$ atualidade, a Educação Ambiental (EA) pode ser entendida como sinônimo de reflexão e ação, que se reflete a partir de uma esfera educativa, permanente e contínua tendo por finalidade, superar a visão unicamente ecológica, transpondo o olhar para uma dimensão mais ampla, com discussões de questões políticas, sociais, econômicas, culturais e ambientais (SPIRONELLO; TAVARES; SILVA. 2012). Dessa forma a EA busca sensibilizar as pessoas a cerca de questões relativas ao meio ambiente, buscando uma transformação no modo de pensar e agir social, tendo em vista à tomada de consciência crítica no entendimento e compreensão da realidade e a complexidade que a engloba (SOUZA, 2014).

Nesse sentido, a escola torna-se um espaço importante de socialização e troca de experiências, de forma que, quanto mais cedo no desenvolvimento infantil a EA for aplicada, maiores as chances de se alcançar uma consciência ambiental bem sucedida. Além de que, a EA aplicada nas crianças possui um efeito multiplicador dentro das famílias e da comunidade a qual estas estão inseridas (TRAVASSOS, 2006; REIGOTA, 2006).

A educação ambiental é um mecanismo indispensável para o sucesso das práticas de sensibilização da sociedade nas temáticas relacionadas aos Resíduos Sólidos (RS). As ações educativas voltadas aos RS resultam na diminuição de problemas ambientais gerados por estes (SOARES; SALGUEIRO; GAZINEU, 2007). Assim, a escola tem como dever instigar o aluno à sensibilização ambiental, buscando uma boa relação com o meio natural e social. Conforme CEMPRE (2006), a Educação Ambiental quanto aos resíduos sólidos deve ser propagada tendo como base os três R's (Reduzir, Reutilizar, Reciclar), sensibilizando e divulgando a sociedade, objetivando a conscientização da mesma.

\section{Metodologia}

O projeto foi executado na Escola Centro de Ensino São Bento, localizada no Endereço: TV. Humaitá, 2996- Bairro do Marco, Município de Belém no estado do Pará. Em uma instituição de ensino privada, o qual foi criada em 15 de dezembro de 2015 segundo seus registros. Seu foco principal é a educação infantil, atuando do maternal até a 5 série do ensino 
fundamental.

No tocante foram selecionadas as turmas do $1^{\circ}$ e $2^{\circ}$ ano do ensino fundamental, uma vez que as atividades propostas estariam mais adequadas faixa etária dessas séries. Afim de introduzir a atividade principal dessa pesquisa, no dia 20 de setembro de 2017 realizou-se uma roda de conversa com as crianças que participariam da oficina de fantoche. Para realização da oficina foram usados os seguintes materiais: Papel colorido do tipo camurça, tesoura sem ponta, cola; fita adesiva e embalagens do tipo longa vida. A oficina de fantoche teve como tema: "Os Animais E O Meio Ambiente".

Com a finalização da oficina de fantoches, cada aluno respondeu a um questionário composto de 6 perguntas fechadas. Para que os mesmo entendesse as questões, cada discente leu e marcou a resposta referente ao respondido pelas crianças

\section{Resultados e Discussão}

Para a realização do presente estudo foram aplicados 30 questionários, entre os alunos do $1^{\circ}$ (15 alunos de ambos os sexos) e $2^{\circ}$ ano (15 alunos de ambos os sexos), que teve como o objetivo de investigar o conhecimento dos alunos a respeito dos resíduos sólidos.

Primeiramente buscou-se verificar se na escola os professores costumam conversar com as crianças a respeito da importância do meio ambiente, assim os alunos do $1^{\circ}$ e $2^{\circ}$ ano responderam da seguinte forma: a maioria (80\% dos entrevistados) ao serem questionadas afirmaram que os professores já haviam feito discussões em sala a respeito do tema referido, apenas $20 \%$ responderam "não". Posteriormente foram indagadas sobre a importância de falar sobre o meio ambiente, em sua totalidade (100\%), responderam ao questionamento de forma afirmativa

Questionados sobre suas ações cotidianas para manter o meio ambiente saudável as crianças não entraram em um consenso. Entre as crianças do $1^{\circ}$ anos, $60 \%$ afirmaram que sua única ação é não jogar lixo no chão, enquanto que o restante afirmou realizar todas as ações citadas na referida questão (não jogar lixo no chão, desligar o chuveiro enquanto se ensaboa/lava o cabelo, desligar o chuveiro enquanto se ensaboa/lava o cabelo, separar o lixo).

No que diz respeito aos alunos $2^{\circ}$ ano, $43 \%$ afirmaram que praticam três das ações citadas (não jogar lixo no chão, desligar o chuveiro enquanto se ensaboa/lava o cabelo e desligar o chuveiro enquanto se ensaboa/lava o cabelo) com exceção da opção c (desligar as luzes quando elas não são necessárias). Tal afirmação não estava presente inicialmente no questionário, mas devido ao número de crianças que afirmavam praticar apenas essas três 
ações, foi necessário essa modificação. É importante notar que a partir disso infere-se que uma grande parcela dos alunos do $2^{\circ}$ ano tem pouca informação a respeito do uso de energia de forma sustentável.

Após os questionamentos a respeito do meio ambiente buscou-se investigar os conhecimentos das crianças a respeito de questões ligadas aos resíduos sólidos. Primeiramente foi indagado as crianças se elas já tinham ouvido falar sobre resíduos sólidos. No $1^{\mathrm{o}}$ ano nenhuma ( $100 \%$ dos entrevistados) criança era familiarizada com o termo resíduo sólido, todas tiveram conhecimento apenas durante a palestra ministrada no dia da oficina. Por outro lado, no $2^{\circ}$ ano $43 \%$ das crianças já ouviram falar desse termo. Diante disso, podemos inferir que entre as turmas existe uma diferença significativa de conhecimentos a respeito de resíduos sólidos.

No que se refere às crianças do $1^{\circ}$ ano não houve uma resposta majoritária, nessa turma as alternativas mais votadas são antagônicas. Enquanto que boa parte das crianças entende a coleta seletiva como o ato de separar o lixo em suas respectivas lixeiras (70\%), outra parte não tem conhecimento a respeito do assunto (30\%)

Por outro lado, apesar de afirmar já terem ouvido o termo "resíduos sólidos", $50 \%$ dos entrevistados do $2^{\circ}$ ano não sabem o que é coleta seletiva, $1 \%$ entendem como "jogar lixo nas lixeiras coloridas", 33\% a coleta regular municipal. Após a investigação a respeita da coleta seletiva, questionou-se as crianças sobre a reciclagem. Os alunos do $1^{\circ}$ ano respondera que, reciclagem é não jogar lixo na rua (20\%), é separar o lixo (40\%), é o aproveitamento de material usado (40\%). Enquanto que os alunos do $2^{\circ}$ ano responderam, é não jogar lixo na rua (14\%), é separar o lixo (0\%), é o aproveitamento de material usado (86\%).

Nesse contexto entende-se que as crianças que participaram da ação realizada por essa pesquisa tem um entendimento superficial sobre as questões ligadas aos resíduos e ao meio ambiente. Durante a palestra ao serem questionadas a respeito de como a escola trata a questão do meio ambiente em sala de aula, as crianças expuseram que tais assuntos são tratados geralmente em datas comemorativas como o dia da arvore ou semana do meio ambiente.

Dessa forma apesar da escola não tratar de maneira continuada a educação ambiental, infere-se que os alunos das séries iniciais caso fosse instituído alguma atividade semanal referente ao meio ambiente participariam ativamente e isso refletiria na futura geração e preservação do meio ambiente. 
No decorrer da oficina as crianças sentiam-se fascinadas com a ideia da construção de fantoches a partir de materiais recicláveis. Ao final, os alunos foram instigados a criar histórias coletivamente sobre os animais e o meio ambiente, entretanto essa atividade foi realizada pela as próprias professoras da escola as quais aproveitaram o resultado final da oficina (Figura 2). Por meio das atividades lúdicas, a criança reproduz muitas situações vividas em seu cotidiano, as quais, pela imaginação e pelo faz de conta, são reelaboradas (JUSTINO \& OLIVEIRA, 2013). Esta representação do cotidiano se dá por meio da combinação entre experiências passadas com novas possibilidades de interpretações e reproduções do real (SANTOS, 2011). Estas ações são fundamentais para a atividade criadora do homem tornando-se um ótimo mecanismo para educar ambientalmente

\section{Conclusões}

Notou-se que após a aplicação das ações premeditadas, as crianças perceberam o quão é importante à manutenção do meio ambiente para sua geração e futuras, na medida em que o mesmo será fundamental à aquisição da sustentabilidade almejada no porvir dos próximos anos. Tendo em vista o reaproveitamento de resíduos sólidos como: caixa de leite e de suco, a fim de confeccionar fantoches de modo dinâmico e atrativo, conseguiu-se pontificar e empoderar os alunos, a respeito da diferença entre resíduos sólidos e lixo, onde e como devem ser descartados corretamente e luzes de opções da reutilização deste material de maneira lúdica. $\mathrm{O}$ estímulo à fabricação desses brinquedos também proporcionou proatividade e domínio aos discentes; com intuito de iniciarem uma jornada que possibilite um horizonte, no qual possam viver a pirâmide sustentável por meio de aprendizados como estes ensinados em sala de aula. Os objetivos preconizados foram bem sucedidos, e as discussões fornecem base para o melhoramento e incentivo do ensino infantil quanto às temáticas voltadas ao ambiente em geral. Desta forma, torna-se de suma importância o apelo para uma educação ambiental de qualidade e crescente em nosso país.

\section{Referências}

CEMPRE - Compromisso Empresarial para a Reciclagem. Programa Bio Consciência. Lixo municipal - Manual de Gerenciamento Integrado. Brasília: CEMPRE, 2006.

JACOBI, P. Meio ambiente urbano e sustentabilidade: alguns elementos para a reflexão. Paulo: Cortez Editora, 1997

JUSTINO, E.; OLIVEIRA, E. A importância do lúdico para educação infantil: uma análise a partir do instituto Desembargador Severino Montenegro. In: Fórum Internacional de Pedagogia. 5. 2013. Salvador - Ba. Anais... Paraiba: Realize, 2013. 
OLIVEIRA, Djalma de Pinho Rebouças de. Planejamento Estratégico. 31 ed. São Paulo: Atlas, 2013.

REIGOTA, M. O Que é educação ambiental. São Paulo, Brasiliense, Coleção Primeiros Passos, 2006.

SANTOS, J. S. O lúdico na educação infantil. In: Fórum Internacional de Pedagogia.4. 2012. Paraíba - PI. Anais... Campina Grande: Realize Editora, 2012

SAUVÉ, L. Educação Ambiental: possibilidades e limitações. Educação e Pesquisa, São Paulo, v. 31, n. 2, p. 317-322, 2005.

SOARES, L. G. C., SALGUEIRO, A. A., GAZINEU, M. H. P. Educação ambiental aplicada aos resíduos sólidos na cidade de Olinda, Pernambuco - um estudo de caso. Revista Ciências \& Tecnologia. n. 1, 2007.

SOUZA, C. Educação Ambiental e as trilhas: Contexto para a educação ambiental. Revista Brasileira de Educação Ambiental (Online), v. 9, p. 239-253, 2014.

SPIRONELLO, R.L.; TAVARES, F. S.; SILVA, E.P. Educação ambiental: da teoria à prática, em busca da sensibilização e conscientização ambiental. Revista Geonorte, v.3, n.4, p.140$152,2012$.

TRAVASSOS, E.G. A prática de educação ambiental nas escolas. Porto Alegre, Mediação, 2006. 